\title{
Old minds, new marketplaces: How evolved psychological mechanisms trigger mismatched food preferences
}

\author{
Michał Folwarczny ${ }^{1}$, Tobias Otterbring ${ }^{2}$, Valdimar Sigurdsson ${ }^{1}$, Lynn K. L. Tan ${ }^{3}$, and \\ Norman P. $\mathrm{Li}^{3}$ \\ ${ }^{1}$ Department of Business Administration, Reykjavik University \\ ${ }^{2}$ Department of Management, University of Agder \& Institute of Retail Economics \\ ${ }^{3}$ School of Social Sciences, Singapore Management University
}

\begin{abstract}
Author Note
Michał Folwarczny (D) https://orcid.org/0000-0002-1686-4933
\end{abstract}

Correspondence concerning this article should be addressed to Michał Folwarczny, Department of Business Administration, Reykjavik University, Menntavegur 1, 101 Reykjavik, Iceland. E-mail: michalf@tuta.io

This project was funded by the Icelandic Research Fund (Doctoral Student Grant to Michał Folwarczny number 206880-051). 


\begin{abstract}
Principally due to unhealthy food choices, almost half of adults worldwide are overweight or obese. Current food retail practices bear some responsibility for such public health issues. We argue that numerous attempts to promote healthy eating have been unsuccessful due to the failure to account for our outdated evolved food selection mechanisms. Building on the evolutionary mismatch hypothesis and contrasting ancestral versus present-day foraging environments, we discuss how marketing activities exploit evolutionarily old food preferences and elicit unhealthy food choices for profit maximization at the expense of public health in terms of food consumption. We conclude by explaining how to mitigate this harmful trend by applying the law of law's leverage to facilitate effective strategies to increase healthy food choices. Notably, we show how evolutionary psychology principles can be used to reconcile competing interests between consumers, retailers, and decision-makers responsible for public health policies.
\end{abstract}

\title{
Public Significance Statement
}

Consumers often make unhealthy food choices, partially because of mismatches between their food preferences that have evolved due to frequent food scarcity in ancestral environments and the ample availability of food products in the current consumption landscape. Marketers often exploit these evolutionarily old food preferences to increase sales of foods and beverages, including unhealthy ones. Accordingly, understanding how evolutionary mismatches operate can inform more efficient policymaking, improve public health, and boost consumer well-being.

Keywords: consumer behavior, evolutionary mismatch, food preferences, food marketing 


\section{Old minds, new marketplaces: How evolved psychological mechanisms trigger mismatched food preferences}

During the past few decades, the obesity rate has tripled worldwide, with $40 \%$ of adults now being overweight or obese (Perkovic et al., 2021; WHO, 2020).

Overconsumption of unhealthy and energy-dense foods is a pivotal contributor to this public health crisis, which begs for urgent development of healthy food systems (Willett et al., 2019). Considering that consumers acquire foods mainly in retail environments, marketers bear a certain degree of responsibility for these public health issues. However, many retailers are concerned with maximizing profits rather than focusing on consumer well-being. On the other hand, governmental agencies have a high interest in developing effective campaigns that promote healthy eating habits - all 193 United Nations member states have agreed to work toward universal healthcare coverage by 2030 (UN, n.d.), which will increase government expenditures related to treating excessive bodyweight consequences such as cardiovascular diseases and certain forms of cancer (WHO, 2020). In this article, we argue that applying an evolutionary perspective to understand consumer behavior - the evolutionary mismatch framework (Li et al., 2018) and the law of law's leverage (Jones, 2001) — is essential to balancing the competing interests between consumers, retailers, and policymakers, such that retailers can profit sustainably from providing available food options that do not compromise consumers' health.

\section{The law of law's leverage}

In line with the law of law's leverage (Jones, 2001), the amount of resources needed to achieve desired behavioral changes is an inverse function of the extent to which the behavior solves adaptive challenges related to survival and reproduction (see Figure 1). Facilitating behaviors that had little adaptive benefits throughout human history is difficult and costly, whereas behaviors that led to solving adaptive challenges need minimal, if any, incentives to occur. In contrast, behaviors that had a high adaptive value in the past are difficult to discourage, whereas even minor deterrents sufficiently prevent 
behaviors that had a marginal adaptive value. Governmental agencies may increase the cost-effectiveness of their policies by leveraging fundamental motives that emerged as a response to adaptive challenges (Griskevicius \& Kenrick, 2013). For example, publishing names of pickpocketers may be cheaper and provide a stronger deterrent than keeping them in custody that ends with a fine, as people are generally more driven to defend their status in groups than to avoid being in custody (Jones, 2001).

Consuming energy-dense foods has been critical for survival in the past when calories were scarce, and average energy expenditure was relatively high compared to that in modern, sedentary lifestyles. Thus, governments do not have to incentivize consuming chocolate bars, burgers, and pizzas that resemble the taste of foods found in nature that had a high value for promoting survival. In contrast, consuming low-calorie foods has been less critical, especially given that an average lifespan was shorter before the advent of modern medicine. Thus, it is more challenging to promote low-calorie, healthier options such as vegetables, berries, and meats that are close to their natural forms over tastier, high-calorie foods that are processed, sweetened, and genetically modified. Policies that governments may offer to promote substituting unhealthy foods with healthier alternatives should, therefore, leverage these evolved food preferences that influence consumers while shopping. An example of applying such strategies can be to offer foods that taste similar and provide the convenience of junk foods like vegan burgers that are lower in sodium and fat than their traditional alternatives. Governmental institutions may further increase the effectiveness of such solutions by creating and publicizing rankings of companies offering the healthiest options, thus rewarding companies and their management with heightened social status. On the other hand, these institutions may create lists of manufacturers adding most sugar, salt, and other unhealthy ingredients to create a "blacklist," with no manufacturers arguably wanting to be located at the bottom of this list. 
Figure 1

The law of law's leverage

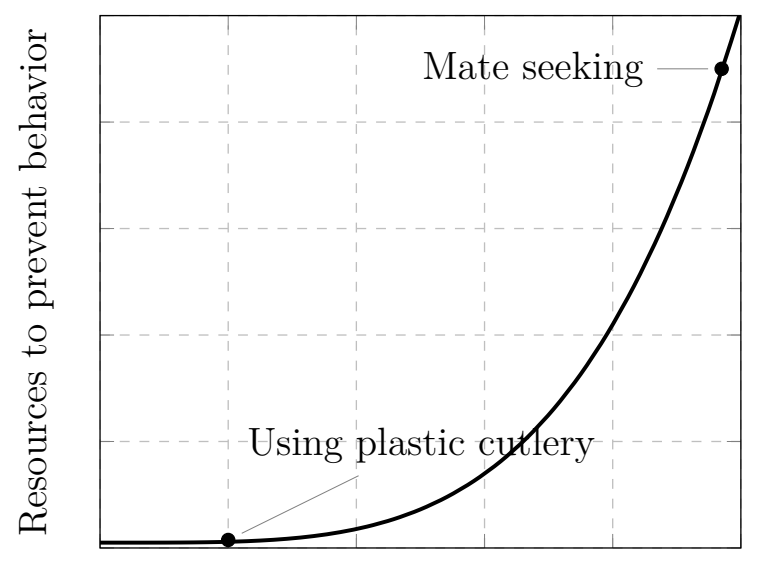

Adaptive value in the past

\section{Adaptations to ancestral foraging environments}

To understand what drives a modern consumer to select specific foods from a plethora of alternatives found among the supermarket shelves, we need to understand the ancestral environments in which our predecessors foraged. Modern homo sapiens emerged approximately 300,000 years ago in Southern Africa (Schlebusch et al., 2017). Ancestral humans lived close to nature in tribes usually not exceeding 150 members (Aiello \& Dunbar, 1993; Dunbar, 1993). Ancient foragers did not enjoy stable access to food resources. Instead, they faced environments that fluctuated between - often lethal-periods of famine and food availability; thus, they had to develop adaptations against times of food scarcity (Rozin, 1996). Even after farming replaced hunting and gathering, humans experienced famine. For instance, "The Year Without Summer" brought massive crop failures that led to worldwide starvation in 1816 (Fagan, 2001).

As a result of an ancestral lineage that largely lived in hostile habitats, modern-day humans still carry food acquisition and bodyweight regulation mechanisms specialized in protecting them against food shortages (but not against food abundance). Thrifty genotype is an example of such adaptation (Neel, 1962; Prentice et al., 2005). This "thriftiness" takes several forms: (1) the metabolism that favors energy-saving; (2) a 
tendency to gain weight quickly; (3) an ability to limit physiological processes to a minimum; (4) a predisposition to consume large amounts of food whenever availability allows; (5) a preference toward physical inactivity to conserve energy; and (6) behaviors aimed at maximizing access to food resources such as food hoarding (Prentice et al., 2005).

According to the insurance hypothesis (Nettle et al., 2017), humans possess adaptive mechanisms that respond to environmental cues to food unavailability. These mechanisms increase energy intake over maintenance levels, contributing to higher energy storage in the form of body fat. However, this adaptation appears to be sex-specific, with food-insecure females more likely than males to be overweight and obese in developed countries (Nettle et al., 2017). This account has received recent empirical support in a series of studies, including preregistered scientific work (Folwarczny, Christensen, et al., 2021; Folwarczny et al., 2020), where exposure to content showing food scarcity distant in time and space prompted participants to immediately prefer higher calorie foods. These findings indicate that humans may react not only to actual food scarcity (cf. Nettle et al., 2017), but also to anticipated food scarcity and perceivable cues linked to such scarcity by shifting their food preferences toward products deemed higher in calories (Folwarczny, Li, et al., 2021).

Unlike specialists eating only one type of food, such as carnivores, humans can consume a wide array of different food options. Thus, when feasting, ancient humans had to select the most nutritious and diverse menus that maximized the chances of surviving an impending famine while minimizing risks associated with consumption-some foods could have been poisonous (Breslin, 2013). Consequently, humans developed a preference toward sweet, salty, and energy-dense foods rich in proteins that provided high doses of nutrients needed for prolonged fasts, but formed an aversion toward sour and bitter tastes, as these flavors may signal that the food contains toxins (Beauchamp et al., 1986; Krebs, 2009; Otterbring, 2021). Although human food preferences have historically been adaptive, these evolved preferences may now lead consumers to indulge in innutritious food products that are available in abundance. Consequently, the nutritional profile of modern-day diets vastly 
differs from that of ancient diets, leading to adverse health outcomes (Eaton \& Konner, 1985). Indeed, consumers tend to prefer high-fat, high-sodium, and high-caloric beef burgers rather than dressing-free salads.

Hunter-gatherers share many similarities in their food preferences with the abovementioned consumers. For instance, the Hadza of Tanzania are hunter-gatherers inhabiting areas where early hominins resided millions of years ago (Berbesque \& Marlowe, 2009). They are opportunistic foragers, usually not seeking specific items. The foods they eat consist of five main categories: honey, meat, berries, baobab, and tubers. High-sugar and energy-dense honey is their preferred food option, whereas tubers rich in complex carbohydrates that are more difficult to digest and lower in energy density are the least preferred food items. Interestingly, the Hadza males prefer honey to a larger extent than do females, who instead value berries more (Berbesque \& Marlowe, 2009). However, due to traditional lifestyles, these hunter-gatherers consume primarily unprocessed foods and moderate amounts of calories; thus, their food preferences remain adaptive.

\section{Mismatches between ancestral and modern foraging}

In contrast to ancestral humans who frequently experienced food scarcity and had to invest a considerable amount of time and energy in finding something to eat, modern consumers "forage" conveniently in supermarkets and usually maintain a substantial amount of food in their refrigerators and pantries. In fact, food has become even more accessible, as the retail sector is shifting to online platforms (Sigurdsson et al., 2017), with this trend accelerating due to the current COVID-19 pandemic (Chang \& Meyerhoefer, 2021). Moreover, the number of products offered by an average supermarket has increased from 9,000 to almost 50,000 between 1975 and 2008, with many products offered in dozens of flavors (Consumer Reports, 2014). On top of that, an average person is exposed to thousands of appetite-inducing ads daily (Story, 2007). Additionally, retailers offer products mimicking supernormal versions of the best-tasting foods found in ancestral environments: over half of the calories Americans consume are ultra-processed, high in 
sodium, and sugar-laden (Steele et al., 2016).

Given the striking differences between ancestral and modern foraging environments, it becomes evident that the rapid change in which food alternatives that typically occupy most consumers' minds (and most supermarket shelves) has outpaced the changes in the specific psychological mechanisms that evolved throughout our evolutionary past (Tooby \& Cosmides, 1990). Consequently, consumers may fail to cope well with various aspects of modern-day food selection challenges. Such a divergence between evolutionary mechanisms specialized to respond to threats and opportunities found in ancestral environments and modern-day stimuli activating these mechanisms frequently leads to maladaptive outcomes or evolutionary mismatches (Li et al., 2018; Li et al., 2020; Van Vugt et al., 2020). Mismatches occur when psychological and physiological mechanisms, which originated to produce adaptive responses to cues and other inputs found in ancestral environments, encounter evolutionarily novel stimuli (Gidlöf et al., 2021). Mismatched psychological mechanisms then produce cognitive, affective, and behavioral responses that may no longer be adaptive and, sometimes, may even be maladaptive, although evolutionarily novel stimuli do not always yield undesired consequences (cf. Kanazawa, 2010).

\section{Policy recommendations}

We argue that applying evolutionarily informed theories may help reconcile the interests of three key stakeholders in the food industry: governmental agencies, retailers, and consumers. The primary interest of governments is to facilitate healthy eating habits to improve public health. Indeed, most countries in the world have agreed to work toward universal health coverage (UN, n.d.), and unhealthy eating results in diseases that are typically extremely expensive to treat at population and national levels (WHO, 2020). Food retailers, like retailers in other industries, strive to maximize their profits. Finally, most consumers express a desire to eat healthier and agree that people tend to eat too much and too unhealthily (Pew Research Center, 2016). Unfortunately, consumers' attempts to change their eating habits usually fail. For example, weight-loss diets typically 
lead to higher body weight subsequently than before starting the program (Mann et al., 2007) and consumers often select cheap, convenient, and tasty foods instead of focusing on healthy nutrition (Wansink \& Huckabee, 2005). These seemingly strange behaviors are understandable if we consider the fact that modern consumers' decision-making machinery has been shaped by thousands of generations of struggle against food unavailability.

\section{Make healthy foods appealing to evolutionarily-shaped taste buds}

Inspired by the evolutionary mismatch framework (Li et al., 2018) and the law of law's leverage (Jones, 2001), we posit that the most promising form of promoting healthy foods consumption is to make them taste as good as or even better than unhealthy options, which usually mimic the taste of sweet, protein-rich, and energy-dense foods found in ancestral environments. Studies show that consumers are only modestly aware of unhealthy snacks being substituted with healthier products at the point of purchase (Winkler et al., 2016). Such interventions increase sales of healthy foods, given that (healthy) product alternatives closely mimick (unhealthy) goods that consumers used to buy before interventions (Hoek et al., 2017; Sigurdsson et al., 2014). Some governments have already introduced policies that facilitate substituting animal-based and unhealthy foods with plant-based and healthier alternatives that closely resemble foods that modern consumers - similar to their ancestors - prefer. For example, Singapore strives to become a global leader in plant-based (cholesterol-free) protein production and consumption - the country's state-owned venture has recently invested significant funds into companies producing plant-based animal meat substitutes (Ramli, 2021). Although the future profitability of companies offering meat alternatives is currently uncertain, the value of Impossible Foods and Beyond Meat that belong to leaders in this industry has already surpassed expectations (Sen \& Franklin, 2021). However, in contrast to Singapore, many countries have merely limited consumers' access to certain products without offering any alternatives. We believe that such attempts will be politically unpopular, as consumers' food preferences which have developed through thousands of generations, cannot be wiped 
out by merely increasing the cost and/or limiting the availability of some products. In fact, higher prices of specific food products may paradoxically make them even more desirable due to the scarcity principle, whereby items that are difficult to access or afford are viewed as more desirable (Lynn, 1991; Otterbring, 2016; Otterbring \& Rolschau, 2021). In the worst case, this may create a rebound effect, where people are more inclined to buy these foods. Additionally, unlike promoting healthy food consumption, imposing taxes on unhealthy foods may hurt the interests of retailers, making them oppose the changes. Retailers can be incentivized to offer more nutritious products, such as snacks made of low-calorie root vegetables seasoned with low-sodium salt instead of omnipresent and unhealthy potato chips. To help retailers stay profitable while phasing out unhealthy foods, governments may financially support them by, for example, offering tax deductions on revenues from healthy foods.

\section{Make healthy food choices convenient}

As our ancestors had to conserve energy (Prentice et al., 2005), they could not direct much attention to foods that were especially challenging to obtain. This may partially explain the worldwide success of fast-food chains such as McDonald's, offering low prices and convenience. These low-cost chain restaurants are often the only options for consumers who frequently live in "food deserts" where healthier alternatives are unavailable or difficult to find, making healthy eating inconvenient. Still, the cost of healthy diets rich in fruits and vegetables is only marginally higher per calorie than the cost of diets filled with unhealthy, "cheap" calories (Rao et al., 2013). Therefore, with adequate governmental incentives, fast-food chains may consider introducing more unprocessed, healthier, and plant-based dishes that are as tasty and convenient as their existing offerings without imposing a higher financial burden on consumers. Additionally, it is crucial to make healthy food more prominent (in terms of attention) and easy to buy (in terms of behavioral and cognitive effort and time). The store layout should make it as easy as possible for consumers to select healthy products. For instance, Sigurdsson et al. (2014) 
conducted experiments in two grocery stores in Norway. The authors substituted sugary snacks in the most convenient places in grocery stores (i.e., check-out counters) with healthier alternatives like dried fruits and dried fish. They found a substantial increase in sales of healthier products and a decrease in sales of sugary snacks. Policymakers may therefore prohibit the sales of foods high in fat and sugar in these locations in grocery stores without lowering overall sales that would harm retailers. In many countries, it is illegal to sell alcohol in grocery stores; thus, similar policies are already applied.

\section{Minimize the impact of food scarcity cues}

Ancestral humans have developed mechanisms sensitive to food scarcity cues (Nettle et al., 2017). Thus, instead of featuring public campaigns that bombard consumers with food scarcity cues, governments can reassure people that shelves will remain full during events such as Brexit or the COVID-19 pandemic. Environmental cues may similarly signal food scarcity and elicit calorie cravings among consumers (Folwarczny, Otterbring, et al., 2021). On the other hand, moving people from poor to more affluent neighborhoods is associated with decreasing obesity rates (Ludwig et al., 2011). Therefore, policies aimed at minimizing economic inequalities may contribute to addressing obesity in societies. Indeed, income inequality and economic insecurity increase the risk of obesity across countries (Nettle et al., 2017).

\section{Limit excessive collaborative consumption of food}

Humans, like many other social living species, usually care for their kin, with many goods and services appealing to this fundamental motive (Griskevicius \& Kenrick, 2013). For example, Dopperlerz - a German health tonic - is often advertised as a gift for family members boosting their vitality. Collaborative consumption with consumers contributing to and eating from a shared pool of food (Parker et al., 2019), is a chance for consumers to show their kin care motivation. However, these generosity displays lead people to buy and consume more foods on average than in private settings, potentially contributing to weight gain and food waste (Parker et al., 2019). Nevertheless, kin care motives may be leveraged 
to lower consumption of unhealthy foods. For example, healthy food sets that will be consumed with others during parties may be advertised similarly to the famous German health tonic, potentially making collaborative consumption a "healthier" event.

\section{Make existing products healthier}

Manufacturers often optimize the amount of sugar, fat, and salt as well as aromas, appearance, and texture of food in a way that maximizes a hedonic pleasure from food consumption, making it more difficult for consumers to stop eating when they are full, mainly because consumers are often unaware of what they are ingesting (Kessler, 2009, p. 140). Therefore, policymakers should help consumers notice the ingredients they ingest. Field experiments have demonstrated that providing calorie information and making healthy foods more convenient to order than unhealthy alternatives reduces overall calorie intake; yet, the effect of convenience is present only when unhealthy options are more challenging to order than healthier alternatives (Wisdom et al., 2010). Thus, such policies may not be feasible and raise ethical concerns regarding consumers' rights. Moreover, it is unlikely that eating healthy belongs to important, adaptive goals that inform myriads of consumer behaviors. Therefore, a more plausible intervention is selling healthier foods "in disguise." For instance, in Finland, some of Kellogg's cereals have 10\% less sugar and sodium than their US alternatives, with few countries using only $20 \%$ of sodium in Kellogg's Honey Snacks that is used in the US (The Center for Science in the Public Interest, 2016).

\section{Educate the public}

Consumers are generally not aware of evolutionary mechanisms driving their food choices; hence, making them aware of these mechanisms can facilitate healthier eating (Ares et al., 2021; Kessler, 2009, p. 247). Four strategies that policymakers can embrace to help consumers make informed food choices are as follows: (1) listing calories of all items in the restaurant menus; (2) labeling foods in such a way that makes information about unhealthy ingredients salient; (3) conducting public education campaigns highlighting 
health risks associated with eating unhealthy foods; and (4) demarketing companies that promote unhealthy products by publicly exposing their business practices (Kessler, 2009, pp. 247-248).

Human behavior is largely driven by self-protection (e.g., avoiding pathogens) motives (Griskevicius \& Kenrick, 2013), which may be used as a way to increase the effectiveness of campaigns aimed at curbing unhealthy eating. For instance, Palomo-Vélez et al. (2018) compared the effectiveness of various messages aimed at discouraging meat consumption. The authors found disgust-oriented messages (e.g., informing consumers that meat has contact with faces in slaughterhouses) more potent in making attitudes toward meat consumption more negative than appeals showing the negative impact of meat consumption on the environment, animal welfare, and health. Disgust-eliciting messages are currently used worldwide in anti-smoking campaigns. Thus, policymakers may use disgust-eliciting messages that show the consequences of eating unhealthy foods, such as showing images of stomach cancer developed due to eating high-sodium products.

\section{If everything fails - use strong incentives}

In some cases - especially when behaviors had a considerable adaptive value in the past-solid governmental interventions are vital for behavioral change (Jones, 2001). Strong interventions have been successful in reducing undesired behaviors in the past. For instance, workplace smoking bans reduced smoking prevalence and the average number of cigarettes consumed daily among smokers (Evans et al., 1999). Regarding food choices, one strategy could be to tax unhealthy ingredients. The UK soft drinks industry levy - a tax imposed on manufacturers, importers, and bottlers of soft drinks, with higher rates for drinks high in sugar and lower rates on less sugary products - reduced an average sugar intake from these drinks by $10 \%$ per household, without impacting overall sales of soft drinks, thus not harming the industry (Pell et al., 2021). Similar policies may be implemented to reduce calories, saturated fat, and salt in other product categories. Manufacturers may be incentivized through grants covered by such taxes to produce 
healthier products appealing to human evolutionarily old taste buds by, for instance, substituting some sugar with stevia.

\section{Conclusion}

Ancestral foragers had to select foods promoting survival in times of frequent food scarcity. As a result, modern consumers inherited these outdated food preferences, which are mismatched against their current needs, with almost half of adults now being overweight or obese. As modern consumers carry food acquisition mechanisms specialized in coping with ancestral challenges, they often fail to perceive threats posed by unhealthy diets, even if these threats are communicated (e.g., nutrition facts labels). Still, retailers - incentivized by governments - can facilitate healthier food choices by applying evolutionarily informed solutions into their marketing mix. 


\section{References}

Aiello, L. C., \& Dunbar, R. I. M. (1993). Neocortex size, group size, and the evolution of language. Current Anthropology, 34 (2), 184-193.

Ares, G., Vidal, L., Otterbring, T., Aschemann-Witzel, J., Curutchet, M. R., Giménez, A., \& Bove, I. (2021). Communication campaigns to support the use of nutritional warnings: Different messages for different people? Health Education 6 B Behavior. https://doi.org/10.1177/10901981211003510

Beauchamp, G. K., Cowart, B. J., \& Moran, M. (1986). Developmental changes in salt acceptability in human infants. Developmental Psychobiology: The Journal of the International Society for Developmental Psychobiology, 19(1), 17-25. https://doi.org/10.1002/dev.420190103

Berbesque, J. C., \& Marlowe, F. W. (2009). Sex differences in food preferences of Hadza hunter-gatherers. Evolutionary Psychology, 7(4), 147470490900700409. https://doi.org/10.1177/147470490900700409

Breslin, P. A. (2013). An evolutionary perspective on food and human taste. Current Biology, 23(9), R409-R418. https://doi.org/10.1016/j.cub.2013.04.010

Chang, H.-H., \& Meyerhoefer, C. D. (2021). COVID-19 and the demand for online food shopping services: Empirical evidence from Taiwan. American Journal of Agricultural Economics, 103(2), 448-465. https://doi.org/10.1111/ajae.12170

Consumer Reports. (2014). What to do when there are too many product choices on the store shelves? https://www.consumerreports.org/cro/magazine/2014/03/too-manyproduct-choices-in-supermarkets/index.htm\#: :text=We\%20eyeballed $\% 2053 \%$ 20varieties., Marketing\%20Institute\%2C\%20a\%20trade\%20group

Dunbar, R. I. M. (1993). Coevolution of neocortical size, group size and language in humans. Behavioral and Brain Sciences, 16(4), 681-694. https://doi.org/10.1017/S0140525X00032325 
Eaton, S. B., \& Konner, M. (1985). Paleolithic nutrition: A consideration of its nature and current implications. New England Journal of Medicine, 312(5), 283-289. https://doi.org/10.1056/NEJM198501313120505

Evans, W. N., Farrelly, M. C., \& Montgomery, E. (1999). Do workplace smoking bans reduce smoking? American Economic Review, 89(4), 728-747. https://doi.org/10.1257/aer.89.4.728

Fagan, B. (2001). The Little Ice Age: how climate made history 1300-1850. Basic Books. Folwarczny, M., Christensen, J. D., Li, N. P., Sigurdsson, V., \& Otterbring, T. (2021). Crisis communication, anticipated food scarcity, and food preferences: Preregistered evidence of the insurance hypothesis. Food Quality and Preference, 91, 104213. https://doi.org/10.1016/j.foodqual.2021.104213

Folwarczny, M., Li, N. P., Sigurdsson, V., Tan, L. K., \& Otterbring, T. (2020). Development and psychometric evaluation of the Anticipated Food Scarcity Scale (AFSS). https://doi.org/10.31234/osf.io/gtx4n

Folwarczny, M., Li, N. P., Sigurdsson, V., Tan, L. K., \& Otterbring, T. (2021). Development and psychometric evaluation of the anticipated food scarcity scale (afss). Appetite, 105474. https://doi.org/10.1016/j.appet.2021.105474

Folwarczny, M., Otterbring, T., Sigurdsson, V., \& Gasiorowska, A. (2021). Seasonal cues to food scarcity and calorie cravings: Winter cues elicit preferences for energy-dense foods. https://doi.org/10.31234/osf.io/72bhy

Gidlöf, K., Ares, G., Aschemann-Witzel, J., \& Otterbring, T. (2021). Give us today our daily bread: The effect of hunger on consumers' visual attention towards bread and the role of time orientation. Food Quality and Preference, 88, 104079. https://doi.org/10.1016/j.foodqual.2020.104079

Griskevicius, V., \& Kenrick, D. T. (2013). Fundamental motives: How evolutionary needs influence consumer behavior. Journal of Consumer Psychology, 23(3), 372-386. https://doi.org/10.1016/j.jcps.2013.03.003 
Hoek, A., Pearson, D., James, S., Lawrence, M., \& Friel, S. (2017). Healthy and environmentally sustainable food choices: Consumer responses to point-of-purchase actions. Food Quality and Preference, 58, 94-106. https://doi.org/10.1016/j.foodqual.2016.12.008

Jones, O. D. (2001). Time-shifted rationality and the law of law's leverage: Behavioral economics meets behavioral biology. Northwestern University Law Review, 95 (4), 1141-1205. https://doi.org/10.2139/ssrn.249419

Kanazawa, S. (2010). Evolutionary psychology and intelligence research. American Psychologist, 65(4), 279-289. https://doi.org/10.1037/a0019378

Kessler, D. A. (2009). The end of overeating: Taking control of the insatiable American appetite. Rodale.

Krebs, J. R. (2009). The gourmet ape: Evolution and human food preferences. The American Journal of Clinical Nutrition, 90(3), 707S-711S. https://doi.org/10.3945/ajcn.2009.27462B

Li, N. P., van Vugt, M., \& Colarelli, S. M. (2018). The evolutionary mismatch hypothesis: Implications for psychological science. Current Directions in Psychological Science, 27(1), 38-44. https://doi.org/10.1177/0963721417731378

Li, N. P., Yong, J. C., \& Van Vugt, M. (2020). Evolutionary psychology's next challenge: Solving modern problems using a mismatch perspective. Evolutionary Behavioral Sciences, 14(4), 362-367. https://doi.org/10.1037/ebs0000207

Ludwig, J., Sanbonmatsu, L., Gennetian, L., Adam, E., Duncan, G. J., Katz, L. F., Kessler, R. C., Kling, J. R., Lindau, S. T., Whitaker, R. C., et al. (2011). Neighborhoods, obesity, and diabetes - a randomized social experiment. New England Journal of Medicine, 365(16), 1509-1519. https://doi.org/10.1056/NEJMsa1103216 
Lynn, M. (1991). Scarcity effects on value: A quantitative review of the commodity theory literature. Psychology \& Marketing, 8(1), 43-57. https://doi.org/10.1002/mar.4220080105

Mann, T., Tomiyama, A. J., Westling, E., Lew, A.-M., Samuels, B., \& Chatman, J. (2007). Medicare's search for effective obesity treatments: Diets are not the answer. American Psychologist, 62(3), 220-233. https://doi.org/10.1037/0003-066X.62.3.220

Neel, J. V. (1962). Diabetes mellitus: A "thrifty" genotype rendered detrimental by "progress"? American Journal of Human Genetics, 14(4), 353-362.

Nettle, D., Andrews, C., \& Bateson, M. (2017). Food insecurity as a driver of obesity in humans: The insurance hypothesis. Behavioral and Brain Sciences, 40. https://doi.org/10.1017/S0140525X16000947

Otterbring, T. (2016). Touch forbidden, consumption allowed: Counter-intuitive effects of touch restrictions on customers' purchase behavior. Food Quality and Preference, 50, 1-6. https://doi.org/10.1016/j.foodqual.2015.12.011

Otterbring, T. (2021). Evolutionary psychology in marketing: Deep, debated, but fancier with fieldwork. Psychology $\&$ Marketing, 38(2), 229-238. https://doi.org/10.1002/mar.21453

Otterbring, T., \& Rolschau, K. (2021). Beauty is in the eye of the beer holder but rarely because of the beer. Personality and Individual Differences, 179, 110921. https://doi.org/10.1016/j.paid.2021.110921

Palomo-Vélez, G., Tybur, J. M., \& Van Vugt, M. (2018). Unsustainable, unhealthy, or disgusting? comparing different persuasive messages against meat consumption. Journal of Environmental Psychology, 58, 63-71. https://doi.org/10.1016/j.jenvp.2018.08.002

Parker, J. R., Umashankar, N., \& Schleicher, M. G. (2019). How and why the collaborative consumption of food leads to overpurchasing, overconsumption, and waste. Journal 
of Public Policy \& Marketing, 38(2), 154-171.

https://doi.org/10.1177/0743915618823783

Pell, D., Mytton, O., Penney, T. L., Briggs, A., Cummins, S., Penn-Jones, C., Rayner, M., Rutter, H., Scarborough, P., Sharp, S. J., et al. (2021). Changes in soft drinks purchased by British households associated with the UK soft drinks industry levy: Controlled interrupted time series analysis. BMJ, 372. https://doi.org/10.1136/bmj.n254

Perkovic, S., Otterbring, T., Schärli, C., \& Pachur, T. (2021). The perception of food products in adolescents, lay adults, and experts: A psychometric approach. Journal of Experimental Psychology: Applied. https://doi.org/10.1037/xap0000384

Pew Research Center. (2016). The new food fights: U.S. public divides over food science. https://www.pewresearch.org/science/2016/12/01/the-new-food-fights/

Prentice, A. M., Rayco-Solon, P., \& Moore, S. E. (2005). Insights from the developing world: Thrifty genotypes and thrifty phenotypes. Proceedings of the Nutrition Society, 64(2), 153-161. https://doi.org/https://doi.org/10.1079/PNS2005421

Ramli, D. (2021). Temasek makes rare seed investment in plant-based chicken maker. https:/ /www.bloomberg.com/news/articles/2021-02-25/temasek-makes-rare-seedinvestment-in-plant-based-chicken-maker

Rao, M., Afshin, A., Singh, G., \& Mozaffarian, D. (2013). Do healthier foods and diet patterns cost more than less healthy options? A systematic review and meta-analysis. BMJ Open, 3(12), e004277. https://doi.org/10.1136/bmjopen-2013-004277

Rozin, P. (1996). Towards a psychology of food and eating: From motivation to module to model to marker, morality, meaning, and metaphor. Current Directions in Psychological Science, 5(1), 18-24. https://doi.org/10.1111/1467-8721.ep10772690

Schlebusch, C. M., Malmström, H., Günther, T., Sjödin, P., Coutinho, A., Edlund, H., Munters, A. R., Vicente, M., Steyn, M., Soodyall, H., et al. (2017). Southern 
African ancient genomes estimate modern human divergence to 350,000 to 260,000 years ago. Science, 358(6363), 652-655. https://doi.org/10.1126/science.aao6266

Sen, A., \& Franklin, J. (2021, April 8). Exclusive: Impossible Foods in talks to list on the stock market - sources. https://www.reuters.com/article/us-impossible-foods-m-aexclusive-idUSKBN2BV2SF

Sigurdsson, V., Larsen, N. M., \& Gunnarsson, D. (2014). Healthy food products at the point of purchase: An in-store experimental analysis. Journal of Applied Behavior Analysis, 47(1), 151-154. https://doi.org/10.1002/jaba.91

Sigurdsson, V., Menon, R. V., \& Fagerstrøm, A. (2017). Online healthy food experiments: Capturing complexity by using choice-based conjoint analysis. The Behavior Analyst, 40(2), 373-391. https://doi.org/10.1007/s40614-017-0114-9

Steele, E. M., Baraldi, L. G., da Costa Louzada, M. L., Moubarac, J.-C., Mozaffarian, D., \& Monteiro, C. A. (2016). Ultra-processed foods and added sugars in the us diet: Evidence from a nationally representative cross-sectional study. BMJ Open, 6(3). https://doi.org/10.1136/bmjopen-2015-009892

Story, L. (2007). Anywhere the eye can see, it's likely to see an ad. https://www.nytimes.com/2007/01/15/business/media/15everywhere.html

The Center for Science in the Public Interest. (2016, November 29). U.S. cereals higher in sugar and sodium than in certain other countries. https://cspinet.org/news/uscereals-higher-sugar-and-sodium-certain-other-countries-20161129

Tooby, J., \& Cosmides, L. (1990). The past explains the present: Emotional adaptations and the structure of ancestral environments. Ethology and Sociobiology, 11(4-5), 375-424. https://doi.org/10.1016/0162-3095(90)90017-Z

UN. (n.d.). Goal 3: Good health and well-being. https://www.un.org/development/desa/disabilities/envision2030-goal3.html

Van Vugt, M., De Vries, L. P., \& Li, N. P. (2020). Nudging evolutionary mismatched behaviors: Implications for social psychology and public policy. In J. P. Forgas, 
W. D. Crano, \& K. Fiedler (Eds.), Applications of social psychology: How social psychology can contribute to the solution of real world problems (pp. 40-57). Taylor \& Francis. https://doi.org/10.4324/9780367816407

Wansink, B., \& Huckabee, M. (2005). De-marketing obesity. California Management Review, 47(4), 6-18. https://doi.org/10.2139/ssrn.2473723

WHO. (2020). Obesity and overweight. https://www.who.int/news-room/fact-sheets/detail/obesity-and-overweight Willett, W., Rockström, J., Loken, B., Springmann, M., Lang, T., Vermeulen, S., Garnett, T., Tilman, D., DeClerck, F., Wood, A., et al. (2019). Food in the Anthropocene: the EAT-Lancet Commission on healthy diets from sustainable food systems. The Lancet, 393(10170), 447-492. https://doi.org/10.1016/S0140-6736(18)31788-4

Winkler, L. L., Christensen, U., Glümer, C., Bloch, P., Mikkelsen, B. E., Wansink, B., \& Toft, U. (2016). Substituting sugar confectionery with fruit and healthy snacks at checkout - a win-win strategy for consumers and food stores? A study on consumer attitudes and sales effects of a healthy supermarket intervention. BMC Public Health, 16(1), 1-12. https://doi.org/10.1186/s12889-016-3849-4

Wisdom, J., Downs, J. S., \& Loewenstein, G. (2010). Promoting healthy choices: Information versus convenience. American Economic Journal: Applied Economics, 2(2), 164-78. https://doi.org/10.1257/app.2.2.164 